\title{
PLANTABILIDADE E PRODUTIVIDADE DE MILHO SOB PALHADA DE AVEIA PRETA DESSECADA EM DIFERENTES ÉPOCAS
}

\author{
ALCIR JOSÉ MODOLO ${ }^{1}$, ANDREI DANIEL ZDZARSKI ${ }^{1}$, MAICON SGARBOSSA ${ }^{1}$, \\ FORTUNATO DE BORTOLI PAGNONCELLI JUNIOR ${ }^{1}$, EMERSON TROGELLO ${ }^{2}$ \\ e RIVANILDO DALLACORT ${ }^{3}$
}

\author{
${ }^{1}$ Universidade Tecnológica Federal do Paraná - UTFPR, Campus Pato Branco, Paraná, \\ alcir@utfpr.edu.br,dz_andrei@hotmail.com,maicon_sgarbossa@hotmail.com,fpagnoncelli@outlook.com \\ ${ }^{2}$ Instituto Federal Goiano - IFGoiano, Campus Morrinhos, Goiás, emerson.trogello@ifgoiano.edu.br \\ ${ }^{3}$ Universidade do Estado de Mato Grosso - UNEMAT, Campus Tangará da Serra, Mato Grosso, rivanildo@unemat.br
}

Revista Brasileira de Milho e Sorgo, v.18, n.3, p. 340-349, 2019

\begin{abstract}
RESUMO - As épocas utilizadas nos manejos de plantas de cobertura podem prejudicar o desempenho das semeadoras e a produtividade de culturas subsequentes, uma vez que propiciam diferentes condições quali e quantitativas de palhada. Nesse contexto, o objetivo do trabalho foi verificar a influência das épocas de dessecação da aveia preta e mecanismos sulcadores na plantabilidade, desenvolvimento e produtividade da cultura do milho. O experimento foi conduzido no delineamento de blocos ao acaso, em esquema fatorial 4 x 2, com 4 repetições. Os tratamentos foram constituídos de quatro épocas de dessecação da aveia, sendo elas $0,15,30$ e 45 dias antes da semeadura do milho e dois mecanismos sulcadores (haste e disco duplo). A antecipação da dessecação da aveia preta melhora as condições de plantabilidade, mas não proporciona aumento na produtividade de grãos. Apesar de o sulcador tipo haste apresentar maior estande de plantas, ele mobiliza muito solo e não apresenta ganho na produtividade em relação ao disco.
\end{abstract}

Palavras-chave: Qualidade de semeadura, sistema de plantio direto, manejo de cobertura, mecanismos sulcadores.

\section{PLANTABILITY AND YIELD OF MAIZE ON BLACK OATS STRAW DESICCATED IN DIFFERENT PERIODS}

\begin{abstract}
The periods of the management of cover crops may affect the performance of the seeders and the productivity of the subsequent crops, since they provide different qualitative and quantitative straw conditions. In this context, the objective of this work was to verify the effect of periods of desiccation of black oat and furrowing mechanisms on plantability, development and productivity of the corn crop. The experiment was conducted in a randomized block design, in a $4 \times 2$ factorial scheme, with 4 replicates. The treatments were composed of four oat desiccation periods $(0,15,30$ and 45 days before sowing the corn) and two furrowing mechanisms (shank and double disc). The anticipation of the desiccation of black oats improved planting conditions but did not provide an increase in grain yield. Although the shank-type furrower presented larger plant stand, it mobilized a lot of soil and did not caused gain in productivity compared to the disk.
\end{abstract}

Keywords: Sowing quality, no-tillage system, cover management, furrowing mechanisms. 
No Estado do Paraná, grande parte das lavouras de milho é cultivada no sistema plantio direto, o qual preconiza a manutenção da cobertura vegetal sobre o solo. Por isso a escolha da espécie adequada de cobertura de solo, assim como o seu correto manejo, pode trazer benefícios no controle de plantas daninhas e desenvolvimento da cultura (Moraes et al., 2013). Na região sudoeste do Paraná, a adoção da aveia preta como cobertura de inverno tem se tornado cada vez maior, fator este relacionado à facilidade de aquisição de sementes, rusticidade da planta, rapidez na formação de biomassa, ciclo adequado e, principalmente, grande quantidade de matéria seca que a planta proporciona (Ziech et al., 2015).

A alta deposição de resíduos de aveia preta pode apresentar um entrave à correta adoção do sistema de plantio direto, uma vez que as semeadoras -adubadoras utilizadas ainda apresentam problemas de funcionamento em alta deposição de biomassa (Trogello, 2014). Desta forma, opta-se, por vezes, por um manejo especial para fracionar, reposicionar e/ou colocar o material vegetal em contato com a superfície do solo, o qual pode ser efetuado com roçadoras, grade niveladora, rolo-faca, triturador de palhas ou com descargas elétricas por meio do Eletroherb ${ }^{\circledR}$. No entanto, o meio mais utilizado é o químico, em razão da sua alta eficiência operacional, baixo custo e controle não só da planta de cobertura, mas de plantas daninhas presentes na área.

Além do método, a época de manejo da espécie de cobertura é um fator importante na plantabilidade da cultura subsequente, uma vez que o bom desenvolvimento da cultura é dependente do bom desempenho da semeadora, pois se a operação de semeadura não for adequada pode ser prejudicado o estande de plantas, com reflexos na produtividade.
A época de manejo da espécie de cobertura influencia ainda a eficiência do mecanismo de corte da semeadora. Acredita-se que tanto a antecipação de 30 a 40 dias quanto o manejo da aveia realizado no dia semeadura facilitem o corte da palhada. Quando o manejo ocorre em um período de tempo intermediário entre os mencionados anteriormente, os resíduos de aveia podem encontrar-se murchos, provocando embuchamento e redução da eficiência de corte. Nesse sentido, Monquero et al. (2010), ao avaliarem cinco épocas de dessecação antes da semeadura da soja (2, 7, 14, 21 e 28 dias), concluíram que a dessecação feita aos 7 e 14 dias ocasionam maior desenvolvimento da cultura, em relação às demais épocas avaliadas.

Ainda, durante o processo de semeadura, vários fatores interferem no estabelecimento da população de plantas e na produtividade da cultura, destacandose a velocidade de operação da máquina e o tipo de mecanismo sulcador a ser utilizado. De acordo com Germino e Benez (2006), as semeadoras-adubadoras existentes no mercado nacional possuem dois tipos de sistemas de abertura de sulco (sulcador disco duplo e do tipo haste). Contudo, Mialhe (2012) destaca o fato de que, em semeadoras de semeadura direta, as características relativas ao comportamento dos abridores de sulco, de forma isolada dos demais componentes, são relativamente pouco estudadas.

Desse modo, o objetivo deste trabalho foi verificar a influência das épocas de dessecação da aveia preta e mecanismos sulcadores tipo haste e disco duplo, na plantabilidade, desenvolvimento e produtividade da cultura do milho.

\section{Material e Métodos}

O experimento foi conduzido durante a safra agrícola 2015/2016, em Latossolo Vermelho distrófico 
(Soil Survey Staff, 2014), com textura muito argilosa (77,4\% de argila, $20,3 \%$ de silte e $2,3 \%$ de areia), cujas características químicas na camada de 0,0 a $20,0 \mathrm{~cm}$ de profundidade resultaram nos seguintes valores: $\mathrm{pH}$ $\left(\mathrm{CaCl}_{2}\right)=4,30 ; \mathrm{MO}\left(\mathrm{g} \mathrm{dm}^{-3}\right)=52,94 ; \mathrm{P}\left(\mathrm{mg} \mathrm{dm}^{-3}\right)=$ 11,$59 ; \mathrm{H}+\mathrm{Al}\left(\mathrm{cmol}_{\mathrm{c}} \mathrm{dm}^{-3}\right)=7,85 ; \mathrm{K}\left(\mathrm{cmol}_{\mathrm{c} \mathrm{dm}} \mathrm{dm}^{-3}\right)=$ 0,36; $\mathrm{Ca}\left(\mathrm{cmol}_{\mathrm{c}} \mathrm{dm}^{-3}\right)=0,90 ; \mathrm{Mg}\left(\mathrm{cmol}_{\mathrm{c}} \mathrm{dm}^{-3}\right)=3,60$; $\mathrm{SB}\left(\mathrm{cmol}_{\mathrm{c}} \mathrm{dm}^{-3}\right)=4,86 ;$ CTC $\left(\mathrm{cmol}_{\mathrm{c}} \mathrm{dm}^{-3}\right)=12,71 \mathrm{e} \mathrm{V}$ $(\%)=38,32$. O clima é subtropical úmido do tipo Cfa, conforme classificação de Köppen. A área tem sua localização definida pelas coordenadas $26^{\circ} 16^{\prime} 36^{\prime \prime} \mathrm{S}$ e $52^{\circ} 41^{\prime} 20^{\prime \prime} \mathrm{W}$, com altitude média de $760 \mathrm{~m}$ e declividade máxima de 3\%. A área experimental está sendo cultivada no sistema plantio direto há mais de quinze anos, com as culturas da soja (Glycine max) e milho (Zea mays) no verão e com aveia preta (Avena strigosa) ou azevém (Lolium multiflorum) no inverno.

Os dados referentes à temperatura média e precipitação pluviométrica, ao longo do período de condução do experimento, estão apresentados na Figura 1.
Utilizou-se o delineamento de blocos ao acaso, em esquema fatorial $4 \times 2$, com 4 repetições, sendo que os tratamentos utilizados foram constituídos de quatro épocas de dessecação da aveia $(0,15,30$ e 45 dias antes do plantio - DAP) e dois mecanismos sulcadores (disco duplo e haste sulcadora) em uma semeadora-adubadora de plantio direto. A área foi dividida em quatro blocos, totalizando 32 unidades experimentais, cada uma com área de $75 \mathrm{~m}^{2}(3,75 \mathrm{x}$ 20,0 m), com espaçamento entre blocos de 10,0 metros, utilizados para manobra e estabilização do conjunto motomecanizado. Cada unidade experimental era composta de cinco linhas de plantio, espaçadas a 70 centímetros entrelinhas, sendo a área útil (10,5 $\mathrm{m}^{2}$ ) formada por cinco metros de comprimento e pelas três linhas centrais de cada unidade experimental.

A cultivar de aveia preta, semeada em 25/05/2015, foi a IAPAR 61 IBIPORÃ, na densidade de 300 sementes por $\mathrm{m}^{2}$. Para seu manejo foi utilizado o herbicida Glifosato Atanor 48, na dose de 2,0 L

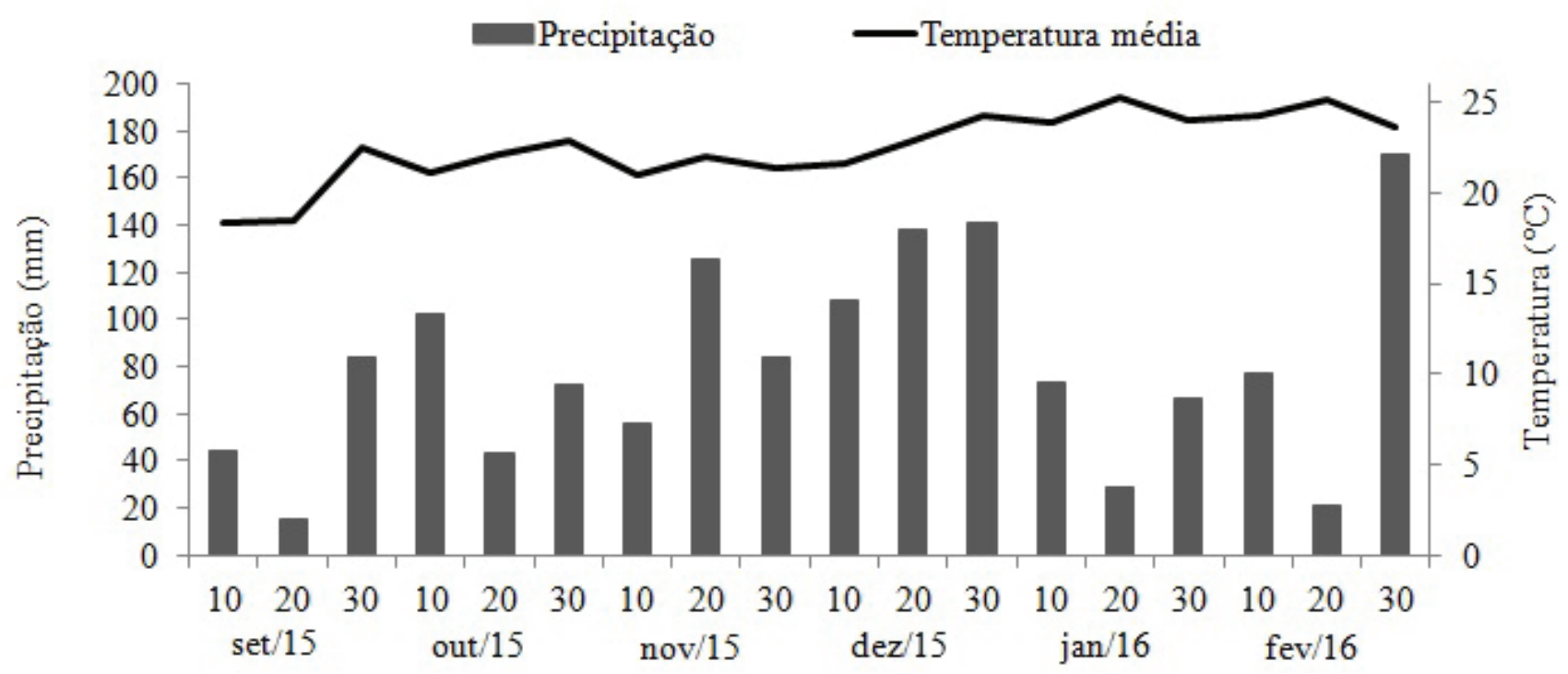

Figura 1. Dados meteorológicos observados durante o período experimental.

Fonte: Instituto Agronômico do Paraná (2018). 
ha $^{-1}$, sendo a dessecação realizada de forma manual, utilizando um pulverizador costal.

O híbrido de milho utilizado foi o Pioneer 30F53VYH, com biotecnologia LEPTRA, com distribuição longitudinal de aproximadamente seis sementes por metro. Na adubação de base foram utilizados $400 \mathrm{Kg} \mathrm{ha}^{-1}$ de adubo granulado NPK, com formulação 08-20-15. Foi realizada a adubação de cobertura, distribuindo-se $300 \mathrm{Kg} \mathrm{ha}^{-1}$ de ureia no estádio V5 (cinco folhas desenvolvidas).

A semeadura do milho foi realizada no dia 23/09/2015, com uma semeadora-adubadora de precisão, marca Vence Tudo, modelo SA 14600, com dosador de sementes do tipo mecânico. Como fonte de potência, utilizou-se um trator New Holland, modelo TL75E, 4x2 TDA (Tração Dianteira Auxiliar), com potência máxima de $57,4 \mathrm{~kW}$ no motor a 2.400 rpm.

Os mecanismos sulcadores utilizados foram do tipo haste com formato parabólico, ângulo de ataque em torno de $20^{\circ}$, espessura da ponteira de $22 \mathrm{~mm}$ de largura e sulcador do tipo discos duplos defasados com 381 mm (15") de diâmetro.

Realizou-se amostragem de matéria seca de aveia preta, antes da semeadura, utilizando um quadro de área conhecida de $0,25 \mathrm{~m}^{2}(0,50 \times 0,50 \mathrm{~m})$. Em cada unidade experimental coletou-se uma amostra. O material coletado foi armazenado em estufa, na temperatura de $65^{\circ} \mathrm{C}$, até peso constante, e depois foi pesado e extrapolado para $\mathrm{kg} \mathrm{ha}^{-1}$.

O perfil de solo mobilizado (profundidade de sulco e área mobilizada) foi determinado com o auxílio de um perfilômetro construído em madeira, com réguas verticais graduadas em centímetros, espaçadas a cada $2 \mathrm{~cm}$ no sentido transversal à linha de semeadura. Verificaram-se os perfis da superfície natural e da superfície final do solo, avaliando as três linhas centrais de cada unidade experimental. Para o cálculo da área mobilizada utilizou-se a equação 1.

$\mathrm{Am}=\sum(\mathrm{PN}-\mathrm{PF}) . \mathrm{e}$

Em que:

Am $=$ Área mobilizada $\left(\mathrm{cm}^{2}\right)$;

$\mathrm{PN}=$ Perfil da superfície natural do solo $(\mathrm{cm})$;

$\mathrm{PF}=$ Perfil da superfície final do solo $(\mathrm{cm})$;

$\mathrm{e}=$ Espaçamento entre réguas verticais $(\mathrm{cm})$.

Para determinação da profundidade de semeadura utilizaram-se as três linhas centrais de cada unidade experimental, avaliando 10 plântulas por linha em estádio de desenvolvimento V3. As plântulas emergidas foram cortadas rente ao solo, e com auxílio de uma espátula realizou-se a retirada da raiz com a semente do solo, medindo-se a distância entre a semente e a região do colmo onde a plântula foi cortada.

Realizou-se a contagem do estande inicial de plantas, quando se apresentou constante o número de plantas emergidas. $\mathrm{O}$ estande final foi avaliado no dia da colheita, contando-se as plantas nas três linhas centrais de cada unidade experimental, em cinco metros de comprimento. O resultado foi ajustado para o número de plantas por hectare.

A altura de plantas foi realizada por meio da distância da superfície do solo até a extensão final do pendão e a altura de inserção da primeira espiga, por meio da distância da base do solo até a inserção da espiga. Para avaliar o diâmetro de colmo foi utilizado um paquímetro digital, realizando-se a medida acima do primeiro entrenó da planta. As medidas foram realizadas em 10 plantas por unidade experimental.

O número de fileiras de grãos foi determinado pela contagem em 10 espigas tomadas ao acaso na área útil de cada unidade experimental. O número de 
grãos por fileira foi determinado mediante contagem dos grãos nas fileiras das 10 espigas amostradas aleatoriamente em cada unidade experimental. Após a debulha foi determinada a massa de mil grãos por meio de 8 amostras de 100 grãos tomadas ao acaso, de cada unidade experimental, as quais foram submetidas à pesagem.

A colheita foi realizada de forma manual quando o milho estava na maturidade fisiológica, colhendo-se $10,5 \mathrm{~m}^{2}$ por parcela, extrapolando-se a produtividade para $\mathrm{kg} \mathrm{ha}^{-1}$.

Os dados foram submetidos à análise de variância pelo teste $\mathrm{F}$ com o aplicativo computacional R (RStudio Team, 2016), utilizando-se do pacote ExpDes.pt (Ferreira et al., 2011). Para os caracteres em que o teste $\mathrm{F}$ apresentou valor significativo a 5\% de probabilidade, as médias foram comparadas pelo teste de Tukey para os fatores qualitativos (sulcadores). Para os fatores quantitativos (épocas de dessecação) aplicou-se o teste de regressão polinomial.

\section{Resultados e Discussão}

A massa seca de aveia apresentou maior quantidade de biomassa na dessecação realizada no dia da semeadura, reduzindo significativamente de acordo com as demais épocas de dessecação, sendo a menor biomassa (3.310 $\left.\mathrm{kg} \mathrm{ha}^{-1}\right)$ obtida quando a dessecação foi realizada aos 45 dias antes da semeadura (Figura 2). Esta menor biomassa ocorreu por causa do maior período em que as plantas permaneceram em campo sob o efeito do herbicida, interrompendo o acúmulo de biomassa e iniciando o processo de decomposição, enquanto as plantas dessecadas no dia da semeadura permaneceram acumulando biomassa.

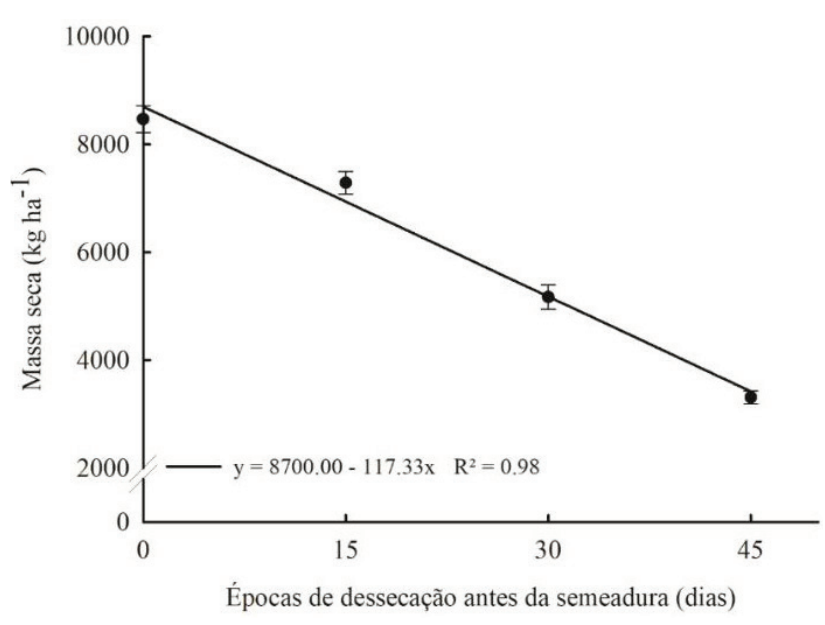

Figura 2. Massa seca de aveia preta $\left(\mathrm{kg} \mathrm{ha}^{-1}\right)$ em função das épocas de dessecação antes da semeadura da cultura do milho.

A deposição irregular da palhada ou até mesmo em quantidades elevadas pode limitar o sistema de semeadura e estabelecimento da cultura (Trogello et al., 2013). De acordo com Nunes et al. (2006), cerca de $6.000 \mathrm{~kg} \mathrm{ha}^{-1}$ são considerados como a quantidade mínima ideal de palhada para a cobertura do solo no sistema plantio direto. Assim, somente os tratamentos 0 e 15 dias antes da semeadura estariam dentro dos padrões ideais para o plantio direto. Desta forma devemos priorizar manejos que disponibilizem maiores quantidades de biomassa no solo, desde que não acarretem problemas para a plantabilidade da cultura.

O sulcador tipo haste apresentou maiores profundidades de semeadura e de sulco, área de solo mobilizada e estandes inicial e final de plantas em relação ao tipo disco (Tabela 1). As maiores profundidades de semeadura e de sulco apresentadas pelo sulcador tipo haste também foram observadas por Mion e Benez (2008), ao trabalharem com diferentes sulcadores. Atribuíram esse resultado ao formato construtivo da haste, que tende a puxar o equipamento para baixo, acarretando maiores profundidades de semeadura. 
A haste apresentou mobilização de 113\% a mais de solo quando comparada ao disco. A maior área de solo mobilizada proporcionada pelo sulcador tipo haste pode ser atribuída à maior profundidade de trabalho obtida (Conte et al., 2009) pela ação diferenciada entre os mecanismos para a abertura do sulco e pelas diferenças entre as características dimensionais dos elementos que interferem nas tensões de corte e cisalhamento (Francetto et al., 2015). Modolo et al. (2013), avaliando parâmetros de plantabilidade na semeadura de milho sob diferentes intensidades de pastejo, observaram que o sulcador tipo haste proporcionou aumento de $46,12 \%$ na área de solo mobilizada, quando comparado ao mecanismo tipo disco duplo.

Os estandes inicial e final de plantas apresentaram diferenças significativas entre os sulcadores, com a haste apresentando maiores valores em relação ao disco. Esse resultado pode estar relacionado ao problema de envelopamento da semente, uma vez que no momento da semeadura foi verificado que o sulcador tipo disco apresentava falhas no corte da palha, depositando-a no fundo do sulco de plantio, não proporcionando o correto contato solo-semente, o que pode ter prejudicado a germinação e posteriormente o estande de plantas. Outra possível explicação é pela haste promover maior mobilização do solo, melhorando o contato da semente com o solo, evitando assim uma compactação na linha de plantio, e também por proporcionar melhor distribuição do adubo na linha em relação ao disco, depositando-o a uma maior distância da semente, evitando assim possíveis danos causados por queima da semente em razão do efeito salino do fertilizante, o qual ocasionaria redução no estande de plantas (Kaneko et al., 2010).

Com relação às épocas de dessecação, temse aumento linear na profundidade de deposição da semente com o aumento no número de dias entre a dessecação e a semeadura (Figura 3a). Quanto maior o intervalo de dessecação da aveia, mais decomposta e seca estava a palhada no momento de semeadura, favorecendo a abertura do sulco e proporcionando a deposição de sementes em maiores profundidades. A palhada que foi dessecada no dia da semeadura apresentava-se verde e não decomposta, o que pode ter impedido o aprofundamento dos sulcadores no solo, fazendo com que a profundidade de semeadura fosse mais superficial. De acordo com Ricce et al. (2011), na semeadura realizada logo após a dessecação pode haver dificuldade na operação das máquinas, dependendo da quantidade de fitomassa da cobertura vegetal.

Tabela 1. Valores médios da profundidade de semeadura (PSM), profundidade de sulco (PSC), área de solo mobilizada (AM), estande inicial (EI) e estande final (EF) em função dos mecanismos sulcadores.

\begin{tabular}{cccccc}
\hline Tratamentos & $\begin{array}{c}\text { PSM } \\
(\mathrm{cm})\end{array}$ & $\begin{array}{c}\text { PSC } \\
(\mathrm{cm})\end{array}$ & $\begin{array}{c}\text { AM } \\
\left(\mathrm{cm}^{2}\right)\end{array}$ & $\begin{array}{c}\text { EI } \\
\left(\mathrm{pl} \mathrm{ha}^{-1}\right)\end{array}$ & $\begin{array}{c}\text { EF } \\
\left(\mathrm{pl} \mathrm{ha}^{-1}\right)\end{array}$ \\
\hline Disco & $5,13 \mathrm{~b}$ & $5,52 \mathrm{~b}$ & $39,39 \mathrm{~b}$ & $72.381 \mathrm{~b}$ & $69.702 \mathrm{~b}$ \\
Haste & $7,17 \mathrm{a}$ & $9,41 \mathrm{a}$ & $83,93 \mathrm{a}$ & $77.500 \mathrm{a}$ & $75.476 \mathrm{a}$ \\
\hline CV $(\%)$ & 9,88 & 16,28 & 22,46 & 7,36 & 8,12 \\
\hline
\end{tabular}

Médias seguidas pela mesma letra minúscula na coluna não diferem significativamente entre si pelo Teste de Tukey a 5\% de probabilidade de erro. 

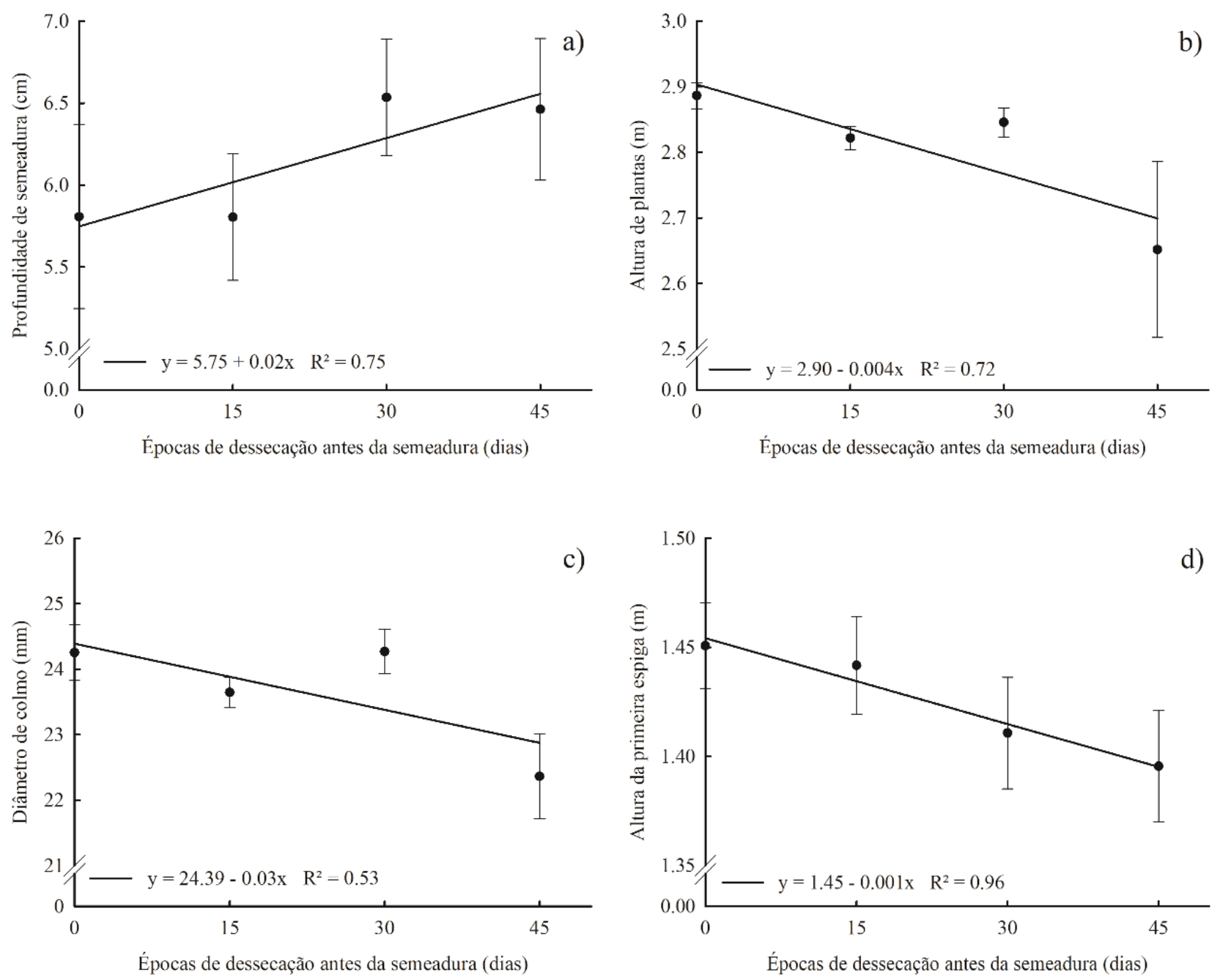

Figura 3. Profundidade de semeadura (a), altura de plantas (b), diâmetro de colmo (c) e altura da primeira espiga (d) em função das épocas de dessecação antes da semeadura da cultura do milho.

A altura de plantas foi influenciada significativamente pelas diferentes épocas de dessecação (Figura 3b), apresentando ajuste linear dos dados, com decréscimo de $6,6 \%$ na altura de plantas entre o intervalo de 0 e 45 DAS. A maior altura de plantas obtida com 0 DAS pode estar relacionada ao estiolamento da planta em condições de sombreamento proporcionado pela presença de palha ereta. Constantin et al. (2008), avaliando os efeitos de doses de glyphosate utilizado na dessecação de manejo de Brachiaria decumbens, no sistema aplique-plante, observaram comportamento semelhante sobre o desenvolvimento inicial da cultura do milho.

O maior diâmetro do colmo foi obtido na dessecação realizada no dia da semeadura (Figura 3c). Resultados semelhantes ao presente trabalho foram encontrados por Kaefer et al. (2012), que concluíram que o diâmetro de colmo diminuiu à medida que o manejo químico é realizado com maior distância da semeadura da cultura do milho, não explicando o re- 
sultado obtido em seu trabalho. Esse caráter deve ser levado em consideração, pois é ele que tem a função de suportar as folhas e as espigas da planta, além de ser uma estrutura que armazena fotoassimilados. Sendo assim, diâmetros de colmos maiores proporcionaram maior formação de grãos e maior sustentação das plantas (Gimenes et al., 2008).

A altura de inserção da primeira espiga apresentou diferenças significativas para as épocas de dessecação, com maior altura sendo obtida na dessecação no dia da semeadura (Figura 3d). Menores alturas de inserção da espiga é uma característica desejável, pois, a espiga estando em menor altura, melhora o equilíbrio da planta, evitando quebras de colmo e acamamento da cultura (Sangoi et al., 2002).

Os mecanismos sulcadores influenciaram significativamente o número de fileiras por espiga e a massa de mil grãos, com o disco apresentando os maiores valores (Tabela 2). O número de fileiras está diretamente relacionado com o estande final de plantas, tendo o mecanismo sulcador tipo haste proporcionado maior estande final de plantas, e consequentemente menor número de fileiras na espiga. Estes dados estão de acordo com os resultados obtidos por Kappes et al. (2011).

Tabela 2. Valores médios do número de fileiras por espiga (NFE), massa de mil grãos (MMG), número de grãos por fileira (NGF) e produtividade (PROD) em função dos mecanismos sulcadores.

\begin{tabular}{ccccc}
\hline Tratamentos & NFE & $\begin{array}{c}\text { MMG } \\
(\mathrm{g})\end{array}$ & NGF & $\begin{array}{c}\text { PROD } \\
\left(\mathrm{kg} \mathrm{ha}^{-1}\right)\end{array}$ \\
\hline Disco & $16,07 \mathrm{a}$ & $323,23 \mathrm{a}$ & 37,33 & 12.321 \\
Haste & $15,72 \mathrm{~b}$ & $314,77 \mathrm{~b}$ & 36,00 & 12.888 \\
\hline CV $(\%)$ & 2,54 & 3,51 & 7,10 & 10,39 \\
\hline
\end{tabular}

Médias seguidas pela mesma letra minúscula na coluna não diferem significativamente entre si pelo Teste de Tukey a 5\% de probabilidade de erro.
Com relação à massa de mil grãos, Borrás e Otegui (2001) afirmam que este componente de rendimento é limitado principalmente por uma característica genética, sendo pouco influenciado por métodos de manejo. Esta constatação não corrobora com os resultados encontrados no presente trabalho, em que o mecanismo sulcador tipo disco proporcionou incremento de 2,69\% na massa de mil grãos em relação à haste sulcadora. Brachtvogel et al. (2009) constataram que o aumento no estande de plantas causa redução na massa de mil grãos das espigas de milho por causa da competição intraespecífica. No presente trabalho, a haste proporcionou maior estande de plantas, ocorrendo uma diminuição na massa de mil grãos à medida que aumentou a população de plantas.

O número de grãos por fileira e a produtividade de grãos não apresentaram diferenças significativas para nenhum dos tratamentos e nem interação entre eles, apresentando valores médios de 36,66 grãos por fileira e produtividade de $12.604,50 \mathrm{~kg} \mathrm{ha}^{-1}$ (Tabela 2). O fato de não haver diferenças na produtividade pode ser explicado pelas diferenças encontradas no estande de plantas e na massa de mil grãos, em que o estande final de plantas foi menor com o uso do sulcador tipo disco, porém, a massa de mil grãos obtida com esse sulcador foi maior, gerando um mecanismo de compensação entre os componentes de rendimento. Supõe-se ainda que a não obtenção de resultados significativos de produtividade possa estar associada à precipitação pluviométrica regular ocorrida em todo o período de desenvolvimento da cultura do milho (Figura 1). Trogello et al. (2013), avaliando manejos de cobertura, mecanismos sulcadores e velocidades de operação sobre a semeadura direta da cultura do milho, também não encontraram diferenças significativas no número de grãos por fileira e na produtividade em nenhum dos tratamentos avaliados. 


\section{Conclusões}

A antecipação da dessecação da aveia preta melhora as condições de plantabilidade, mas não proporciona aumento na produtividade de grãos.

Apesar de o sulcador tipo haste apresentar maior estande de plantas, ele mobiliza muito solo e não apresenta ganho na produtividade em relação ao disco.

\section{Agradecimentos}

Ao $\mathrm{CNPq}$ (bolsa de produtividade) e à Fundação Araucária, pela ajuda financeira para o desenvolvimento do trabalho.

\section{Referências}

BORRÁS, L.; OTEGUI, M. E. Maize kernel weight response to post-flowering source-sink ratio. Crop Science, Madison, v. 41, n. 6, p. 1816-1822, 2001.

DOI: $10.2135 /$ cropsci2001.1816.

BRACHTVOGEL, E. L.; PEREIRA, F. R. S.; CRUZ, S. C. S.; BICUDO, S. J. Densidades populacionais de milho em arranjos espaciais convencional e equidistante entre plantas. Ciência Rural, Santa Maria, v. 39, n. 8, p. 23342339, 2009. DOI: 10.1590/S0103-84782009005000193.

CONSTANTIN, J.; MACHADO, M. H.; CAVALIERI, S. D.; OLIVEIRA JÚNIOR, R. S.; RIOS, F. A.; ROSO, A. C. Influência do glyphosate na dessecação de capimbraquiária e sobre o desenvolvimento inicial da cultura do milho. Planta Daninha, Viçosa, v. 26, n. 3, p. 627-636, 2008. DOI: $10.1590 / \mathrm{S} 0100-83582008000300019$.

CONTE, O.; LEVIEN, R.; TREIN, C. R.; XAVIER, A. A. P.; DEBIASI, H. Demanda de tração, mobilização de solo na linha de semeadura e rendimento da soja, em plantio direto. Pesquisa Agropecuária Brasileira, Brasília, DF, v. 44, n. 10, p. 1254-1261, 2009.

DOI: 10.1590/S0100-204X2009001000007.
FERREIRA, E. B.; CAVALCANTI, P. P.; NOGUEIRA, D. A. ExpDes: experimental designs package R package version 1.1.1. 2011. Disponível em: $<$ https://cran.r-project. org/web/packages/ExpDes.pt/ExpDes.pt.pdf $>$. Acesso em: 19 out. 2016.

FRANCETTO, T. R.; ALONÇO, A. dos S.; BELLÉ, M. P.; FRANCK, C. J.; CARPES, D. P. Comportamento operacional de associações entre sulcadores e discos de corte para sistema de semeadura direta. Engenharia Agrícola, Jaboticabal, v. 35, n. 3, p. 542-554, 2015. DOI:10.1590/1809-4430-Eng.Agric.v35n3p542-554/2015.

GERMINO, R.; BENEZ, S. H. Ensaio comparativo em dois modelos de hastes sulcadoras para semeadoras-adubadoras de plantio direto. Revista Energia na Agricultura, Botucatu, v. 21, n. 3, p. 85-92, 2006.

GIMENES, M. J.; VICTORIA FILHO, R.; PRADO, E. P.; DAL POGETTO, M. H. F. A.; CHRISTOVAM, R. S. Interferência de espécies forrageiras em consórcio com a cultura do milho. Revista da FZVA, Uruguaiana, v. 15, n. 2, p. 61-76, 2008.

INSTITUTO AGRONÔMICO DO PARANÁ. Agrometeorologia. 2018. Disponível em: $<$ http://www. iapar.br >. Acesso em 13 mar. 2018.

KAEFER, J. E.; GUIMARÃES, V. F.; RICHART, A.; CAMPAGNOLO, R.; WENDLING, T. A. Influência das épocas de manejo químico da aveia-preta sobre a incidência de plantas daninhas e desempenho produtivo do milho. Semina: Ciências Agrárias, Londrina, v. 33, n. 2, p. 481-490, 2012.

DOI: $10.5433 / 1679-0359.2012 v 33 n 2 p 481$.

KANEKO, F. H.; ARF, O.; GITTI, D. C.; ARF, M. V.; FERREIRA, J. P.; BUZETTI, S. Mecanismos de abertura de sulcos, inoculação e adubação nitrogenada em feijoeiro em sistema plantio direto. Bragantia, Campinas, v. 69, $\mathrm{n}$. 1, p. 125-133, 2010.

DOI: $10.1590 / \mathrm{S} 0006-87052010000100017$.

KAPPES, C.; ANDRADE, J. A. C.; ARF, O.; OLIVEIRA, A. C.; ARF, M. V.; FERREIRA, J. P. Arranjo de plantas 
para diferentes híbridos de milho. Pesquisa Agropecuária Tropical, Goiânia, v. 41, n. 3, p. 348-359, 2011.

DOI: $10.5216 /$ pat.v41i3.9650.

MIALHE, L. G. Máquinas agrícolas para plantio. Campinas: Millennium, 2012. 623 p.

MION, R. L.; BENEZ, S. H. Esforços em ferramentas rompedoras de solo de semeadoras de plantio direto. Ciência e Agrotecnologia, Lavras, v. 32, n. 5, p. 15941600, 2008. DOI: 10.1590/S1413-70542008000500036.

MODOLO, A. J.; FRANCHIN, M. F.; TROGELLO, E.; ADAMI, P. F.; SCARSI, M.; CARNIELETTO, R. Semeadura de milho com dois mecanismos sulcadores sob diferentes intensidades de pastejo. Engenharia Agrícola, Jaboticabal, v. 33, n. 6, p. 1200-1209, 2013.

DOI: $10.1590 / \mathrm{S} 0100-69162013000600013$.

MONQUERO, P. A.; MILAN, B.; SILVA, P. V.; HIRATA, A. C. S. Intervalo de dessecação de espécies de cobertura do solo antecedendo a semeadura da soja. Planta Daninha, Viçosa, v. 28, n. 3, p. 561-573, 2010.

DOI: $10.1590 / \mathrm{S} 0100-83582010000300013$.

MORAES, P. V. D. de.; AGOSTINETTO, D.; PANOZZO, L. E.; OLIVEIRA, C.; VIGNOLO, G. K.; MARKUS, C. Manejo de plantas de cobertura no controle de plantas daninhas e desempenho produtivo da cultura do milho. Semina: Ciências Agrárias, Londrina, v. 34, n. 2, p. 497 508, 2013. DOI: 10.5433/1679-0359.2013v34n2p497.

NUNES, U. R.; ANDRADE JÚNIOR, V. C.; SILVA, E. de B.; SANTOS, N. F.; COSTA, H. A. O.; FERREIRA, C. A. Produção de palhada de plantas de cobertura e rendimento do feijão em plantio direto. Pesquisa Agropecuária Brasileira, Brasília, DF, v. 41, n. 6, p. 943-948, 2006. DOI: $10.1590 / \mathrm{S} 0100-204 X 2006000600007$.
RICCE, W. da S.; ALVES, S. J.; PRETE, C. E. C. Época de dessecação de pastagem de inverno e produtividade de grãos de soja. Pesquisa Agropecuária Brasileira, Brasília, DF, v. 46, n. 10, p. 1220-1225, 2011.

DOI: 10.1590/S0100-204X2011001000015.

RSTUDIO TEAM. Integrated development for $\mathbf{R}$. Disponível em: < http://www.rstudio.com>. Acesso em: 19 out. 2016.

SANGOI, L.; ALMEIDA, M. L.; GRACIETTI, M. A.; BIANCHET, P. Sustentabilidade do colmo em híbridos de milho de diferentes épocas de cultivo em função da densidade de plantas. Revista de Ciências Agroveterinárias, Lages, v. 1, n. 2, p. 60-66, 2002.

SOIL SURVEY STAFF. Keys to soil taxonomy. 12th ed. Washington: USDA Natural Resources Conservation Service, 2014. 372 p.

TROGELLO, E. Épocas e formas de manejo da aveiapreta na semeadura e produtividade do milho. 2014. 49 f. Tese (Doutorado em Fitotecnia) - Universidade Federal de Viçosa, Viçosa, MG, 2014.

TROGELlO, E.; MODOLO, A. J.; SCARSI, M.; DALLACORT, R. Manejos de cobertura, mecanismos sulcadores e velocidades de operação sobre a semeadura direta da cultura do milho. Bragantia, Campinas, v. 72, n. 1, p. 101-109, 2013.

DOI: $10.1590 / \mathrm{S} 0006-87052013005000016$.

ZIECH, A. R. D.; CONCEIÇÃO, P. C.; LUCHESE, A. V.; BALIN, N. M.; CANDIOTTO, G.; GARMUS, T. G. Proteção do solo por plantas de cobertura de ciclo hibernal na região Sul do Brasil. Pesquisa Agropecuária Brasileira, Brasília, DF, v. 50, n. 5, p. 374-382, 2015. DOI: $10.1590 / \mathrm{S} 0100-204 X 2015000500004$. 